\title{
MOVIMENTOS FEMINISTA, NEGRO E LGBTI NO BRASIL: SUJEITOS, TEIAS E ENQUADRAMENTOS
}

\author{
Regina FACCHINI ${ }^{1}$ \\ ÍrIS NERY DO CARMO ${ }^{2}$ \\ Stephanie Pereira Lima ${ }^{3}$
}

\begin{abstract}
RESUMO: Este artigo examina processos de mudança nos movimentos feminista, negro e no atualmente conhecido como LGBTI. Objetiva produzir aproximações comparativas sobre a produção de enquadramentos e as formas de organização de cada um deles, considerando suas trajetórias nas últimas quatro décadas. É dada ênfase especial aos anos recentes e ao modo como as noções de experiência e interseccionalidade têm operado no período pós-2010, notadamente em iniciativas ativistas protagonizadas por jovens. Para tanto, lança-se mão de uma perspectiva teórica relacional e processual, em diálogo com estudos socioantropológicos que têm se debruçado sobre movimentos sociais. O artigo se baseia em material etnográfico e revisão de literatura.
\end{abstract}

Palavras-chave: Feminismo. Movimento negro. Movimento LGBTI. Enquadramentos. Interseccionalidade.

\section{FEMINIST, BLACK, AND LGBTI MOVEMENTS IN BRAZIL: SUBJECTS, NETWORKS, AND FRAMES}

\begin{abstract}
This article focuses on processes of change in feminist and black movements, as well as in what is known currently as the LGBTI movement. It aims to produce comparative approximations on the production of frames and the organizational forms of each movement, considering their trajectories in the last four decades. Special emphasis is given to recent years and to the way the notions of experience and intersectionality have operated in the post-2010 period, notably in activist initiatives led by young people. To this end, it is used a relational and
\end{abstract}

\footnotetext{
Este artigo está baseado nas pesquisas: Coprodução de Conhecimento sobre Gênero e Sexualidade no Brasil: Ativismos e Relações com a Ciência (CNPq, processo n. 311985/2017-3) coordenada por Regina Facchini; O Rolê Feminista: Autonomia, Horizontalidade e Produção de Sujeito no Campo Feminista Contemporâneo (FAPESP, processo n. 2014/24947-0) coordenada por Íris N. do Carmo; e A gende não é só negro!: interssecionalidade, experiência e afetos na ação política de negros universitários (CNPq, processo n. 870382/1997-7) coordenada por Stephanie Pereira de Lima.

1.Universidade Estadual de Campinas - Programa de Pós-Graduação em Ciências Sociais - Núcleo de Estudos de Gênero Pagu - Campinas (SP), Brasil. E-mail: re.facchini@gmail.com

2.Universidade Estadual de Campinas - Programa de Pós-Graduação em Ciências Sociais - Núcleo de Estudos de Gênero Pagu - Campinas (SP), Brasil. E-mail: irisndocarmo@gmail.com

3.Universidade Estadual de Campinas - Programa de Pós-Graduação em Ciências Sociais - Núcleo de Estudos de Gênero Pagu - Campinas (SP), Brasil. E-mail: lima.p.stephanie@gmail.com
} 
processual theoretical framework, dialoguing with socio-anthropological studies that have focused on movements. The article is based on ethnographic material and literature review.

Keywords: Feminism. Black movement. LGBTI movement. Frames. Intersectionality.

\section{MOVIMIENTOS FEMINISTAS, NEGROS Y LGBTI EN BRASIL: SUJETOS, REDES Y MARCOS INTERPRETATIVOS}

RESUMEN: Este artículo se centra en los procesos de cambio en los movimientos feminista, negro y lo que actualmente se conoce como movimiento LGBTI. Su objetivo es producir aproximaciones comparativas sobre la producción de marcos interpretativos y las formas de organización de cada uno de ellos, considerando sus trayectorias en las últimas cuatro décadas. Se pone especial énfasis en los últimos años y la forma en que la nociones de experiencia e interseccionalidad han funcionado en el período posterior a 2010, especialmente en las iniciativas activistas dirigidas por jóvenes. Para tanto, utilizase una perspectiva teórica relacional y procesal, en diálogo con estudios socioantropológicos que se han centrado en los movimientos sociales. El artículo se basa en material etnográfico y revisión de literatura.

Palabras-clave: Feminismo. Movimiento negro. Movimiento LGBTI. Marcos. Interseccionalidad.

\section{Introdução}

Nos últimos 40 anos, passamos a conviver, no Brasil, com um conjunto de iniciativas que foram identificadas na literatura como "novos movimentos sociais" ou "alternativos", por oposição a formatos "mais tradicionais" de participação política. Tais movimentos foram, algumas vezes, classificados, ainda, como "identitários", sendo também recorrentemente acusados de divisionismo. Não retomaremos a crítica ao baixo rendimento analítico da dicotomia implicada nessas classificações, em geral marcadas por hierarquizações, entre "econômico" e "cultural" (FACCHINI, 2005). Contudo, sua existência é um ponto de partida para a reunião do conjunto de movimentos sobre o qual nos debruçamos.

Este artigo enfoca as trajetórias de três movimentos sociais - o movimento feminista, o movimento negro e o movimento atualmente conhecido como LGBTI - nas últimas quatro décadas. Embora se faça valer de um olhar retrospectivo e acabe por indicar momentos nos quais determinadas características predominam, não é seu objetivo construir ou disputar narrativas históricas: as periodizações delineadas tiveram como foco permitir aproximações comparativas sobre a produção de enquadramentos nos movimentos abordados. A análise da produção de enquadramentos é seu foco principal e especial atenção é dirigida para o modo como as noções de experiência e interseccionalidade têm operado na atualidade.

Oartigo sevale, paratanto, deuma perspectiva teóricarelacionale processual, elegendo comolente a metáfora de um emaranhado de teias constituídas por um conjunto heterogêneo de atores e perpassadas por fluxos discursivos (delinguagem, práticas e sentidos), como proposto por Alvarez (2014). A referência 
à heterogeneidade dos atores se apoia em reflexões que enfatizam o aspecto relacional (SANTOS, 1977; CARDOSO, 1987; DOIMO, 1995; FACCHINI, 2005; AGUIÃO, 2018) e procura escapar à associação entre movimento social e dados formatos ou atores.

Considera, ainda, como indica Das (2011), que os processos de se tornar sujeito constituem-se por experiências de sujeição marcadas pela violência mais ou menos extraordinária. O engajamento político em movimentos sociais é tomado como um entre vários modos de reinscrever a própria história e construir possibilidades de voltar a habitar um mundo devastado pela violência ou por apagamentos e exclusões. As iniciativas sobre as quais nos debruçamos são, assim, consideradas instâncias pedagógicas do aprendizado emocional e da (re)organização social do sofrimento (FERREIRA, 2016). Desse modo, os processos de produção de enquadramentos emergem, de modo indissociável, de disputas pelo melhor modo de dizer de si, dos seus(suas) e de suas demandas em determinados contextos. Este texto se baseia em material etnográfico e em revisão de literatura sobre cada um dos movimentos, produzidos para pesquisas conduzidas por cada uma das autoras.

\section{Processos de Centramento, Tensões e Articulações}

Os movimentos abordados aqui têm processos de surgimento e trajetórias diferentes; também são diversas as convenções acerca do que configura um movimento produzidas pela literatura sobre cada um deles. Embora a reflexão seja relevante, sobretudo neste momento, no qual análises apontam um "descentramento da forma-movimento" (BRINGEL, 2018), ela ultrapassa nosso escopo. Contudo, é importante assinalar que são diversos os modos, os critérios e, possivelmente, as motivações para produzir delimitações do que é tido como movimento social. Tais delimitações variam ao longo do tempo, inclusive em relação a um mesmo movimento, como destaca Figueiredo (2018). Para fins da aproximação comparativa proposta, partiremos do recorte temporal dos anos 1970, seguindo as convenções que indicam aí a emergência das "versões contemporâneas" dos movimentos analisados.

Sonia Alvarez (2014) argumenta que um "feminismo no singular" se forjava no país e na América Latina nas décadas de 1970 e 1980, localizado no campo mais amplo de oposição às ditaduras no continente e tendo como demandas principais o fim da subordinação da mulher, o fim do regime militar, a anistia, os direitos humanos e o direito ao aborto.

Um eixo discursivo central naquele momento girava em torno da tradução de questões tidas como íntimas e privadas em temas e demandas de cunho político. Tal estratégia estava no centro das controvérsias que envolviam outros atores inseridos na luta de oposição ao regime, em meio à qual feministas se esforçavam por demarcar um espaço político próprio, por meio de coletivos autônomos. Como decorrência, eram, com frequência, apontadas como um "desvio pequeno-burguês" por aqueles que viam a "questão da mulher" como uma contradição secundária (ALVAREZ, 2014).

O conflito em torno do que representava a autonomia, na época, orientava também a relação com outras mulheres, que não se apresentavam como feministas (ALVAREZ, 2014). No interior dessas e de outras tensões, que envolviam principalmente mulheres negras e lésbicas (GONZALEZ, 1988; MÍCCOLIS; DANIEL, 1983), o feminismo consolidava aquele que, duas décadas depois, seria considerado o seu maior patrimônio político: a categoria de representação mulher (COSTA, 1998). Isso é visível no âmbito das respostas políticas que emergem a partir do diálogo socioestatal. Em 1983, surge o primeiro Conselho da Condição Feminina. Contudo, as políticas que se seguem adotam a categoria mulher(es): Conselho 
Nacional de Defesa da Mulher (1984); Programa de Assistência Integral à Saúde da Mulher (1985); Delegacias Especializadas de Atendimento às Mulheres Vítimas da Violência (a primeira DEAM foi criada em São Paulo em 1986).

Apesar da dominância da reivindicação da categoria mulher, importantes intelectuais e ativistas negras e lésbicas disputavam o campo feminista nos anos 1980. Embora a leitura, a posteriori, aponte o "centramento" como resultante desses processos de disputa, aqui, como no caso do movimento homossexual e, com menor intensidade, do movimento negro, considerar tais tensões é importante para entender as participações e escritos daquele contexto, tanto quanto os desdobramentos posteriores em torno de sujeitos políticos como mulheres negras, lésbicas, negros(as) LGBTI (MACRAE, 1990; RODRIGUES; PRADO, 2010).

A década de 1970 é também considerada o momento de formação do movimento negro contemporâneo, com a criação do Movimento Negro Unificado (MNU), em 1978 (GONZALEZ, 1982; DOMINGUES, 2007; PEREIRA, 2010; GIACOMINI, TERRA, 2014). Entre as contribuições do MNU, Figueiredo (2018) aponta: a desmistificação da mestiçagem; a crítica à democracia racial brasileira; o combate aos estereótipos raciais; a demanda pela introdução da História da África e do Negro no Brasil nos currículos escolares; a ressignificação do termo negro para autoclassificação da cor no Brasil. A autora de estaca, ainda, que a popularização desse termo está intimamente relacionada às questões de afirmação da identidade negra.

Analisando as categorias de identificação mobilizadas pelo movimento negro entre 1889 e 2000, Domingues (2007) indica que, nos períodos que antecedem 1978, a criação do MNU e a adoção "oficial" da categoria negro, as categorias homem de cor, preto e negro foram mobilizadas por iniciativas ativistas de formatos variados. Assim como no movimento feminista, é possível identificar também um processo de "centramento" em torno da categoria negro.

Contudo, o centramento em torno de uma categoria que aponta a especificidade do movimento não indica um tipo de fechamento a relações com outros movimentos ou com pautas que incluam outras especificidades. Tanto Gonzalez quanto Domingues ressaltam a articulação com setores de esquerda na criação do MNU. Embora Gonzalez (1982) sublinhe como marco a "articulação entre raça e classe", a própria autora e os documentos do MNU (p. ex., sua Carta de Princípios) reconheciam, naquele momento, a presença de outras articulações: Gonzalez (1982) se refere muitas vezes às mulheres negras, e a Carta menciona mulher negra e menores ${ }^{1}$, além da questão do trabalho e a da situação de presidiários.

Na década de 1980, com a conquista de espaços institucionais, mantém-se a coexistência entre especificidades e articulação com outros movimentos e pautas. As primeiras conquistas nessa direção ocorrem em São Paulo e Rio de Janeiro, com a criação de assessorias e comissões e o lançamento de candidaturas para o Legislativo. Boa parte das atividades públicas do centenário da Abolição (1988), por exemplo, ocorreram em espaços institucionais, como universidades, bibliotecas e museus. Os eventos contaram, também, com contribuições de militantes negros alocados no interior de espaços de participação socioestatal, como o Conselho da Condição Feminina e o Conselho da Comunidade Negra, criado em 1984 (RIOS, 2008). A partir de 1986, houve participação ativa do movimento negro no processo da Constituinte, resultando na criminalização do racismo no reconhecimento tanto aos remanescentes de quilombos quanto à propriedade definitiva das terras que ocupam. Em 1988, criou-se o primeiro órgão federal voltado para questões raciais, a Fundação Palmares, e, ao fim da década, surgem as primeiras ONG negras. As articulações com questões de gênero e de classe podem ser localizadas ao longo de todo o processo, marcado pelo centramento em torno da categoria negro. 
No que concerne ao movimento homossexual, as primeiras iniciativas ativistas reconhecidas como explicitamente politizadas datam do fim dos anos 1970 (MACRAE, 1990), embora sejam registradas, desde os anos 1950, formas de associativismo dedicadas à sociabilidade, bem como publicações artesanais em grandes cidades (GREEN, 2000; SIMÕES; FACCHINI, 2009) e tentativas de articulação de congressos homossexuais ou travestis em Minas Gerais, Rio de Janeiro, Bahia, Paraíba e Ceará na segunda metade dos anos 1960 (RODRIGUES, 2018). Chama atenção, nessa literatura, a mobilização de outras categorias, como libertados do amor ou terceiro sexo, as quais tendem a desaparecer no momento seguinte.

Ressalvada a memória das disputas que perpassam tal processo e o caracterizam como atravessado por um equilíbrio bastante instável, é possível estabelecer certa analogia ao momento de "centramento", no qual se configura um "feminismo no singular" em torno da categoria mulher (ALVAREZ, 2014) ou se articula uma especificidade em torno do significante negro (GONZALEZ, 1982), bem como um processo que se desenrola no então chamado movimento homossexual brasileiro (ou MHB): das tensões entre ser ou estar homossexual, presentes nos primeiros grupos de reflexão e de afirmação de fins dos anos 1970 (FRY; MACRAE, 1983; MACRAE, 1990; MÍCCOLIS; DANIEL, 1983), passa-se à apropriação e ao forjamento da categoria orientação sexual como significante até certo ponto esvaziado da conotação essencialista que marcava sua origem, o que se deu nos anos 1980 (CÂMARA, 2002; FACCHINI, 2005).

Outras tensões nos primeiros grupos ativistas homossexuais remetiam tanto à representação de questões de gênero e de raça na prática cotidiana quanto a diferentes projetos de transformação social, opondo autonomistas e socialistas (MACRAE, 1990; GREEN, 2000; SIMÕES; FACCHINI, 2009). A partir de meados dos anos 1980, apesar da redução expressiva da quantidade de grupos e das dificuldades trazidas pela chegada da epidemia do HIV/Aids, há mudanças significativas, com o crescimento da influência de ativistas cuja atuação é mais pragmática e dirigida aos direitos das(os) homossexuais (FACCHINI, 2005).

É fundamental, nesse processo de "centramento", ou de produção de um sujeito político estável, a campanha que levou à obtenção de parecer do Conselho Federal de Medicina (CFM), em 1985, orientando os médicos quanto à codificação não patologizante da homossexualidade na vigência da CID-92. A demanda pela não discriminação por orientação sexual, levada à Constituinte de 19871988, e a luta pelo direito à vida, representada pelas demandas de combate à epidemia do HIV/Aids e à violência letal, colocaram em cena a mobilização da categoria orientação sexual (CÂMARA, 2002). Tal mobilização procurava apaziguar as tensões em torno de perspectivas mais essencialistas e das que atribuíam centralidade a processos sociais de constituição da subjetividade e/ou do desejo (FACCHINI, 2005). Todavia, deixava em aberto as intersecções entre sexualidade, gênero e raça, que já haviam demonstrado sua importância desde os primeiros momentos do movimento, bem como as tensões em torno da estabilidade da identidade sexual e do encapsulamento da potencial fluidez do desejo.

Se havia esforços na direção da produção de sujeitos políticos estáveis, com foco em especificidades, havia também alianças e pautas compartilhadas entre movimentos ditos de minorias categoria utilizada de maneira a aglutinar tais lutas - e significativa presença de setores de esquerda e da questão de classe nos processos de constituição, de pautas e em ações promovidas por cada um dos movimentos. Em 10 de março de 1979, por exemplo, o jornal Lampião da Esquina noticiava debates realizados na Universidade de São Paulo: "Negros, mulheres, homossexuais e índios nos debates da USP: Felicidade também deve ser ampla e irrestrita”. Rios e Maciel (2018) indicam que os coletivos de mulheres negras, que emergiram naquele período, mantinham identidade coletiva autônoma em relação ao feminismo e ao movimento negro, embora nutrissem forte interdependência política relacionada 
às organizações feministas e antirracistas, além de outras bases, como as eclesiais, as sindicais e as comunitárias. Os homossexuais negros, mas, sobretudo, as lésbicas e mulheres negras emergiam como sujeitos complexos e traziam consigo o prenúncio de tensões envolvendo as diferenças na diferença. Tais tensões aparecem com maior força nas décadas seguintes, com o adensamento dos processos de redemocratização, de "cidadanização" ${ }^{3}$ dos sujeitos políticos dos movimentos e de participação socioestatal.

\section{Cidadanização, Institucionalização e Descentramento}

Os anos 1990 e 2000 assistem a processos simultâneos de adensamento da participação socioestatal, de cidadanização desses sujeitos políticos, bem como um "descentramento" que implica a complexificação na definição dos sujeitos políticos dos movimentos sociais analisados. Tais mudanças foram possíveis, no âmbito nacional, graças à redemocratização e ao desenvolvimento de mecanismos de participação e diálogo socioestatal, com o envolvimento de movimentos sociais na formulação, na implementação e na avaliação de políticas públicas e o consequente processo de institucionalização das organizações. Ainda nesse momento, intensificaram-se lançamentos de candidaturas, proposições de projetos de lei e incidências políticas dirigidas principalmente ao Legislativo e ao Executivo, mas também ao Judiciário.

O processo de reconhecimento dos sujeitos dos movimentos como sujeitos de direitos se desenvolve, com variações para os movimentos abordados, como desdobramento dos ciclos de mobilização relacionados à Constituinte, sendo concomitante à abertura de espaços de diálogo e participação socioestatal (p. ex., comitês e conselhos). O ápice do processo de "cidadanização" se dá nos anos 2000, com a criação de estruturas de gestão dedicadas a políticas para mulheres, igualdade racial e combate à homofobia, além da convocação de conferências, em âmbitos municipal, estadual e federal, destinadas a embasar a formulação e a avaliação de políticas públicas.

Internacionalmente, é fundamental um cenário relativamente permeável aos direitos sexuais e reprodutivos e a debates sobre racismo e intolerâncias correlatas, no âmbito das Nações Unidas ${ }^{4}$ (CORRÊA, 2009, 2018; BLACKWELL; NABER, 2002). O período que se inicia nos anos 1990 é também de fortalecimento e ampliação de redes transnacionais de atuação. Assim, a formalização das organizações ativistas era, ao mesmo tempo, estimulada pelos processos de participação socioestatal e apoiada por redes e organizações internacionais.

Ao olhar para o movimento feminista latino-americano, Alvarez (2014) assinala um movimento de reconfiguração desse campo, na medida em que ativistas, discursos e práticas feministas começam a se articular verticalmente em direção aos partidos, governos, universidades e órgãos de cooperação internacional, tendo o gênero como categoria a ser transversalizada ou mainstreamed. Contudo, o uso de tal categoria conviveu com um intenso processo interno de diferenciação e diversificação: as "outras" do feminismo do primeiro momento se configuram como "outros feminismos", dado o significativo alargamento do campo mobilizado por mulheres negras, lésbicas, sindicalistas, do campo, entre outras.

Rios e Maciel (2018), ao tratarem do feminismo negro no Brasil, chamam atenção para a formalização das organizações, a constituição de redes transnacionais e o aumento da relação com o Estado, sobretudo com a criação da Secretaria de Políticas para Mulheres (SPM) e da Secretaria de Políticas para a Promoção da Igualdade Racial (SEPPIR), em 2003. Tendo em vista a formulação e a implementação de políticas públicas, emerge, nesse contexto, a rede de Negras Jovens Feministas, movendo-se via ONG, conferências e espaços de mediação socioestatal.

O intenso processo de diversificação de identidades, que tem lugar no movimento até então conhecido como homossexual, contribui para uma reflexão sobre o "descentramento". O diálogo socioestatal, 
que se desenvolvia desde a criação de políticas públicas de prevenção ao HIV/Aids para homens que fazem sexo com homens no início dos anos 1990, exigia clara delimitação de sujeitos e demandas (FACCHINI, 2005). Tais processos levaram a duas respostas por parte do movimento.

A primeira foi uma ênfase na clara delimitação de identidades e o consequente acirramento dos processos de disputa por visibilidade no interior de um movimento no qual o sujeito político se tornava mais e mais complexo. Multiplicaram-se as redes nacionais e regionais de organizações, mas também as letras do acrônimo que nomeava o movimento, cuja ordem se estabiliza apenas com a adoção da formulação LGBT - lésbicas, gays, bissexuais, travestis e transexuais - na I Conferência Nacional de Políticas para LGBT, de 2008 (FACCHINI, 2009). Criam-se, ainda, articulações entre LGBT e outros segmentos populacionais, de modo a constituir grupos e redes de negras(os) e jovens LGBT.

A segunda resposta foi a visibilidade massiva protagonizada pelas Paradas do Orgulho, o que é, em parte, complementar à incidência política, visto que dava corpo, por assim dizer, à comunidade, mas também a dotava de uma face mais plural, produzindo deslocamentos em relação a repertórios como a exposição pública de ativistas assumidos e a enquadramentos que passam a ser tidos como vitimistas (FACCHINI, 2005).

A difusão de todo um vocabulário marcado por categorias como populações, segmentos, especificidades e transversalidade nas gramáticas estatais incorporadas pelo movimento e as disputas por recursos sempre escassos faziam com que comitês técnicos e plenárias de conferências constituíssem espaços privilegiados de conflito e pactuação, de construção da unidade (AGUIÃO, 2018). Eram também espaços de intensa luta classificatória e de esforços por criar pontes entre classificações oficiais e formas de autoatribuição encontradas nas bases (LOPES; HEREDIA, 2014). Silvia Aguião (2018) chama atenção para a criação e recriação de morfologias de Estado e de coprodução entre sujeitos e direitos que subjazem ao processo de cidadanização. Assim, emergem demandas pelo reconhecimento da necessidade de combater especificamente a lesbofobia e a transfobia, conduzindo, no fim desse momento, em 2016, ao emprego da categoria LGBTfobia.

No movimento negro também nota-se crescente diálogo com esferas estatais, visando à proposição de políticas de inclusão racial (GIACOMINI; TERRA, 2014), bem como expansão e diversificação do movimento negro, traduzidas na formação de novas organizações e na composição dos coletivos de mulheres negras que levaram à ampliação do repertório do movimento, com a inclusão de questões relativas a gênero e sexualidade (RIOS, 2017). Nota-se, ainda, a articulação entre incidência política e mobilizações de rua para a inserção e o alargamento da agenda de igualdade racial, como na ocasião da Marcha do Tricentenário da Morte de Zumbi, realizada em 1995, a qual levou a Brasília ativistas do movimento negro, do movimento de mulheres negras, de sindicatos e de comunidades negras rurais e teve como desdobramento a assinatura do decreto de criação do GT interministerial para política de valorização da população negra pelo então presidente Fernando Henrique Cardoso (RIOS, 2017).

A década de 1990 assistiu a uma intensa formação de ONG ligadas ao movimento negro, em um processo de institucionalização favorecido por incentivos políticos e econômicos internacionais à luta antirracista (RIOS, 2017; GIACOMINI; TERRA, 2014), além dos pré-vestibulares para negros e carentes (PVNC), que se diferenciavam por ter como base o trabalho voluntário de professores e coordenadores de seus núcleos (PEREIRA, 2010). Assim como no movimento feminista e no LGBT, diversos integrantes dessas organizações passaram a compor conselhos de políticas públicas. No caso do movimento negro, tratava-se do Conselho Nacional de Promoção da Igualdade Racial (CNPIR), criado em 2003. Os eixos de demandas do movimento no período aliam "política de reconhecimento (de diferenças raciais e culturais), política de identidade (racialismo e voto étnico), política de cidadania (combate à discriminação racial e afirmação dos 
direitos civis dos negros) e política redistributiva (ações afirmativas ou compensatórias)" (GUIMARÃES, 2001, p. 135).

Reconhecidos como ápice do processo de cidadanização de negros, mulheres e LGBT, os anos 2000 se iniciam com a III Conferência Mundial de Combate ao Racismo, Discriminação Racial, Xenofobia e Intolerância Correlata, realizada em Durban, na África do Sul, em 2001. Essa conferência é um marco da intensificação do processo de adoção de políticas afirmativas no Brasil, levando à criação, no mesmo ano, do primeiro programa de cotas. Considerada um divisor de águas na orientação de estratégias do ativismo negro nacional e internacional, bem como um ápice da atuação política internacional dos negros (RIOS, 2014), a Conferência de Durban gerou reflexos em diversos movimentos sociais no Brasil. Segundo Facchini (2009), além de a noção de intolerância correlata ter permitido a inserção formal de demandas de LGBT na agenda política brasileira, essa conferência trouxe uma importante inflexão no olhar para a promoção de direitos humanos, com impacto na gramática política estatal e dos movimentos: várias formas de intolerância podem se entrecruzar ou potencializar mutuamente.

Nos anos 2000, são criados órgãos governamentais destinados a gerir políticas públicas. Além da Secretaria de Estado dos Direitos Humanos, criada em 1997, no segundo governo de Fernando Henrique Cardoso, são criados a Secretaria de Estado dos Direitos da Mulher, vinculada ao Ministério da Justiça, em 2002, e o GT interministerial para política de valorização da população negra. No primeiro governo de Luiz Inácio Lula da Silva, são criadas a SPM, a SEPPIR e a SEDH (Secretaria Especial de Direitos Humanos), que mantiveram status de ministério entre 2003 e 2015. Ao longo das gestões de Lula, deu-se também a ampliação das formas de participação, com a convocação de conferências de políticas públicas, que foram base para a elaboração de planos nacionais de políticas para as mulheres, para a igualdade racial e para a população LGBT.

Como exemplos de importantes conquistas desse período, temos: as cotas por sexo para processos eleitorais (1997); a Lei Maria da Penha (2006); a implantação de sistemas de notificação de violência contra a mulher; a alteração da tipificação penal do estupro (2009); a lei que tipifica o feminicídio como qualificadora do crime de homicídio (2015); o acesso a mudanças corporais para pessoas transexuais no SUS; o desenvolvimento de políticas de saúde para os LGBT; as portarias que reconhecem o direito ao uso do nome social por travestis e transexuais; a democratização do Ensino Superior, com a criação do Programa Universidade para Todos (Prouni) e do Programa de Apoio a Planos de Reestruturação e Expansão das Universidades Federais (Reuni); o reconhecimento da constitucionalidade da Lei de Cotas (2012) e das "uniões homoafetivas" pelo Supremo Tribunal Federal (STF); e a criação de políticas para a formação continuada de professores e editais de pesquisa, que abordaram, de modo transversal, a igualdade racial e de gênero e a diversidade sexual.

Como assinalam Lopes e Heredia (2014), considerando diversos movimentos sociais, o processo de inclusão crescente a partir do Estado, que se configura no período pós-redemocratização, traz não somente novas necessidades de afirmação identitária, com repercussões sobre a reconstrução permanente da relação com as bases, mas afeta o conjunto das relações no interior do movimento. A participação institucional seria marcada tanto por competição quanto por aprendizados mútuos nas relações entre movimentos, no interior de um movimento e na relação com atores estatais. Trata-se, como assinala Aguião (2018), de um processo que produz saberes e expertises, mas também os contornos dos próprios atores movimento, gestores e Estado - como os entendemos. Além do conhecimento profundo do funcionamento e da dinâmica dos canais de participação e do aprendizado de que o Estado e o governo são atravessados por porosidades e ambiguidades que podem ser exploradas, esse processo leva a uma circulação muito grande de ideias e práticas entre movimentos e administração pública, influenciando o repertório dos atores (LOPES; HEREDIA, 2014). 
A produção de uma "gramática oficial" da participação e as desconfianças relacionadas a possibilidades de cooptação, reflexões que consideram a relação profundamente desigual entre Estado e movimentos, bem como inquietações com relação aos limites dos espaços de participação e ao escopo efetivamente alcançado pelas políticas, passam a produzir controvérsias no interior dos movimentos (AGUIÃO et al., 2014; GIACOMINI; TERRA, 2014; MACHADO, 2016; GUTERRES et al., 2014).

Na virada do milênio, soma-se a esse panorama a chamada "fuga de investimentos". O financiamento da cooperação internacional passou por forte declínio nos anos 2000 em função do crescimento econômico da região - constituindo, nas palavras de Alvarez (2014), um “desincentivo material” aos formatos mais institucionalizados de participação e organização.

Intensificavam-se, também, os sinais de uma "politização reativa" do campo religioso (VAGGIONE, 2017) e da articulação dessa reação com outros atores políticos. Trata-se, como reporta a literatura, de um processo transnacional que se inicia com uma reação aos avanços dos direitos sexuais e reprodutivos, ainda no âmbito das conferências das Nações Unidas, em meados dos anos 1990; que segue em âmbito internacional em paralelo a todo o processo de cidadanização desses sujeitos no Brasil (CORRÊA, 2018); e que vai se articulando a outras bandeiras e interesses, até chegar à articulação entre atores e linhas de força, descritos por Almeida (2017), os quais, aqui e num processo transnacional, mantêm ao centro a política sexual (PRADO; CORRÊA, 2018).

\section{Crise da Democracia, Mudanças na Estrutura de Oportunidades e nos Repertórios e Enquadramentos}

Isso nos leva ao cenário atual, atravessado, inicialmente, por forte desilusão com a política institucional, relacionada a um processo de criminalização da política, processo esse, por sua vez, alimentado por persistentes denúncias de corrupção, sobretudo acerca das gestões do Partido do Trabalhadores no Executivo Federal. Tal desilusão se fazia sentir no cotidiano de ativistas, tanto pela desconfiança com que eram olhados por outros setores e atores mais críticos à centralidade da participação socioestatal quanto pela percepção do caráter limitado dos resultados obtidos por meio de tal engajamento em mecanismos de participação. A isso, contudo, seguiram-se o processo de impeachment contra a presidenta Dilma Rousseff e o violento e rápido ataque a estruturas governamentais, garantias legislativas e direitos, mas também a lideranças e formas de organização políticas que visavam combater e corrigir desigualdades sociais no Brasil. Esse é um processo que afeta profundamente a estrutura de oportunidades para os movimentos dos quais tratamos e que se desdobrou e se aprofundou com a eleição de Jair Bolsonaro à presidência do país.

Nesse processo, têm sido observados um alargamento da compreensão do que é ativismo e uma diversificação nos seus modos de ação, muitos dos quais deixam de ter na figura do Estado o principal interlocutor. Tal mudança poderia ser pensada em sua relação com transformações da estrutura de oportunidades no tocante ao desmonte de estruturas de participação e ao ataque aberto a movimentos sociais. Contudo, ao remetermos à literatura, é possível perceber continuidades em relação a processos de transformação que se faziam sentir desde a década anterior, como reações de setores dos feminismos e dos ativismos de jovens à intensa institucionalização e à centralidade das apostas no diálogo socioestatal.

No que diz respeito aos feminismos, temos o processo crítico de cunho anticapitalista, o qual fez emergir a Marcha Mundial de Mulheres e a Marcha das Margaridas, a partir da virada para os anos 2000, bem como manifestações mais recentes: Marcha das Vadias e Marcha das Mulheres Negras (ALVAREZ, 2014; AGUIAR, 2015; RIOS; MACIEL, 2018; GOMES, 2018; FIGUEIREDO, 2018). No campo do ativismo LGBT, 
são descritas reações críticas à institucionalização tecidas por iniciativas majoritariamente compostas por jovens ou estudantes universitários (LIMA, 2016; DANILIAUSKAS, 2016). Lopes e Heredia (2014) também identificam críticas à institucionalização entre setores dos movimentos de juventude.

Tais reações, que ganham corpo e visibilidade nos anos 2000, em setores anticapitalistas, no movimento antiglobalização e/ou apoiados nos queer studies, fortalecem-se na última década, intensificando as críticas à institucionalização dos movimentos sociais e mesmo à possibilidade de representação política, com desvalorização do "essencialismo estratégico" e descrédito das possibilidades de obtenção de direitos via diálogo com instâncias estatais (ALVAREZ, 2014; GOMES, 2018; FACCHINI, 2018; RIOS; MACIEL, 2018).

Essas críticas estão relacionadas ao questionamento da noção de "movimentos sociais". Pesquisas conduzidas em meados dos anos 2010, com iniciativas compostas, majoritariamente, por jovens feministas e/ou LGBT, encontraram em campo a recusa ao uso da categoria movimento social em relação ao que faziam (LIMA, 2016; CARMO, 2018b; GOMES, 2018). Silva (2018) localiza, em uma rede de empreendedores negros, a passagem de categorias como movimento negro e movimentos negros para a de negros em movimento.

No rastro dessas mudanças, a possibilidade de atuação individual - e seu questionamento - é expressa em diferenciações entre ativistas e militantes, que aludem a, respectivamente, atuações individuais ou coletivas (ZANOLI, 2015; FALCÃO, 2017; LIMA, 2016). Bulgarelli (2017) e Gomes (2018) indicam como, a partir do ciberativismo e da ênfase na ação direta, o lugar mais visível ocupado por organizações e coletivos cedia espaço a "lideranças carismáticas", muitas das quais passam a investir em diferentes carreiras políticas, seja como influenciadores digitais ou por meio do lançamento de candidaturas ao Legislativo.

A plasticidade das iniciativas ativistas e a ruptura da dicotomia entre "ativistas" e "público a que se destinam ações” - que teve seu ponto máximo nas ONG dos anos 1990 e 2000 - são notáveis nos estudos que enfocam feminismos anticapitalistas ou movimentos compostos majoritariamente por jovens. Ao estudar um grupo de sociabilidade LGBT universitário na plataforma Facebook, Falcão (2017) aponta um processo no qual o "campo", no sentido que lhe atribui Swartz (1968), expande-se de tal modo a corresponder à "arena": todos eram, ao mesmo tempo, público interessado nas ações e potenciais agentes com centralidade nos processos políticos de âmbito local observados. Ao registrar a trajetória de 13 anos de atuação do Encontro Nacional Universitário por Diversidade Sexual e de Gênero (ENUDSG), Lima (2016) revela a centralidade de formas não institucionalizadas de atuação os coletivos - e da experiência em processos de formação via vivência, que se dão por meio de situações compartilhadas no cotidiano, nos coletivos e em encontros nacionais de periodicidade anual.

Tais características operam de tal modo que Carmo (2018a, 2018b) teve de reconhecer as limitações da categoria movimentos sociais e dos sentidos e conceitualizações a ela relacionados, evocando, analiticamente, a categoria êmica rolê feminista. O rolê inclui jovens que se apresentam a partir de uma série de adjetivações, acionadas contingencialmente - feministas autônomas, feministas lésbicas, feministas libertárias, anarcafeministas, feministas veganas, feministas punks, feminismo gordo, feminismo faça você mesma, entre outras -, e que buscam distanciar-se de agentes cujas práticas e discursos são percebidos como autoritários - termo geralmente mobilizado para fazer alusão a militantes de gerações anteriores, com atuação próxima a partidos políticos, instituições e sindicatos. Orientado pela autonomia e o faça você mesma como pedagogia política, o rolê tem como estratégia a ocupação da rua, das redes e do corpo, a partir de experimentações coletivas que jogam com as fronteiras entre o público-privado e a relação espaço-tempo. 
Desde a década anterior, com a diversificação dos movimentos em torno das categorias jovem e juventude, notava-se uma intensificação das polarizações geracionais, envolvendo repertórios e mesmo enquadramentos (FACCHINI; FRANÇA 2011). Ainda que processos de colaboração intergeracional pareçam se intensificar com o crescimento do reacionarismo e das ameaças à democracia (CARVALHO; CARRARA, 2015; DANILIAUSKAS, 2016; LIMA, 2016; GOMES, 2018; CARMO, 2018b; RIOS; MACIEL, 2018; FACCHINI, 2018; FIGUEIREDO, 2018), temos pelo menos duas décadas de reconfiguração de repertórios e enquadramentos com base na crítica ao investimento prioritário em formatos, repertórios e enquadramentos que privilegiem a institucionalidade, o diálogo socioestatal e o essencialismo estratégico.

Contudo, há outras transformações relevantes em curso nesse mesmo período, relacionadas aos modos de produção e circulação de conhecimento. Nas gerações mais jovens de ativistas, notam-se mais intensamente os efeitos da popularização da Internet e do uso que dela tem sido feito por atores políticos. A primeira metade dos anos 2010 foi intensamente marcada pelo ciberativismo e por tretas e lacração nas redes sociais (CARVALHO, 2017; FALCÃO, 2017; BULGARELLI, 2017), o que, assim como a celebração da espontaneidade das redes e das ruas, perde um pouco de centralidade no âmbito dos movimentos ditos progressistas, com o aprofundamento dos ataques à democracia e o manejo das redes sociais por atores conservadores ou reacionários.

No âmbito da produção e da circulação do conhecimento, notam-se intensamente os efeitos da ampliação do acesso ao Ensino Superior, bem como do acesso facilitado a aportes teóricos, com destaque para a difusão dos estudos queer, de teorias interseccionais e decoloniais e do feminismo negro (FACCHINI, 2018). O conhecimento produzido no âmbito das universidades tem sido afetado por mudanças que implicam forte articulação entre corpo, política e produção do conhecimento ${ }^{5}$, o que não pode ser dissociado da implementação de ações afirmativas para estudantes oriundos de camadas populares, negros e indígenas, bem como do nome social para travestis e transexuais nos exames de acesso e na documentação acadêmica. Não se trata apenas de referências que adentram o espaço das universidades, mas de sua circulação por variadas formas e meios, referências essas que passam a subsidiar a produção de enquadramentos políticos. Isso se dá em meio a disputas que enfatizam a pesquisa útil e ao estímulo ao anti-intelectualismo (FACCHINI, 2018).

A noção de lugar de fala e as categorias cisgênero e cisnormatividade são exemplos de construtos que tiveram por base a apropriação de reflexões produzidas no âmbito de estudos pós-coloniais, decoloniais e dos transgender studies e que obtiveram ampla difusão por meio de redes sociais, tornando-se centrais em debates que ultrapassaram as redes feministas e LGBT. A apropriação e a mobilização da noção de lugar de fala deslocam o modo negociado como se vinha produzindo a relação entre diferenças relativas a gênero e raça, bem como as visibilidades, colocando, como enfatiza Gomes (2018), o corpo ao centro para autorizar ou barrar a aparição dos sujeitos. Emergem também processos de construção de um "outro não marcado", protagonizado por sujeitos cuja visibilidade foi insistentemente negada, como no caso da produção e da mobilização das categorias cisgênero e cisnormatividade por ativistas trans, como mostram Vergueiro (2015), Carvalho (2017), Coacci (2018) e Bagagli (2019).

A apropriação de recursos teóricos, que, em geral, dá-se via tradução e circulação parcializada de obras em blogs e páginas de redes sociais, debates em grupos on-line ou mesmo pela produção de memes, vê-se acompanhada pela emergência de clivagens que remetem a filiações intelectuais, como transfeminismo, feminismo interseccional ou radical, indicados como intersec ou rad em embates nas redes sociais. Algumas dessas clivagens podem atuar como categorias de identidade e articular, em torno de si, campos discursivos de ação mais ou menos separados. Um caso interessante é o que tem como base a categoria interseccionalidade. 


\section{A Centralidade do Corpo, da Experiência e o Combate a Todas as Opressões}

Interseccionalidade é uma categoria de análise reconhecida como uma das mais importantes contribuições do pensamento feminista para o pensamento social. É fruto de intensos debates políticos e intelectuais no âmbito dos feminismos que se desdobram a partir das críticas de feministas negras, nos anos 1970, à estabilidade homogeneizante da categoria mulher, enfatizando as articulações com raça, classe e sexualidade, entre outras diferenciações sociais.

Entre as novas coletividades feministas negras que ganham visibilidade na segunda década dos anos 2000, Rios e Maciel (2018) chamam atenção para as que se classificam como feministas interseccionais. De acordo com as autoras, tal clivagem viria funcionando, naquele contexto, como uma identidade política, abarcando coletivos feministas periféricos ou universitários, compostos por mulheres negras na faixa etária entre 20 e 30 anos, e voltados à discussão de questões ligadas a racismo, machismo, homofobia, transfobia e visibilidade lésbica. As autoras assinalam, ainda, que, mesmo que não se trate de uma completa ruptura, a formação de redes de feministas interseccionais tensiona formas mais estabelecidas do feminismo negro forjado no contexto de oposição ao regime militar, assim como aquele que se consolidou no período de estabelecimento democrático no país.

O acionamento dessa categoria, porém, nem sempre está relacionado a uma clivagem identitária. Pesquisas etnográficas têm apontado outro modo de operação, que se articula a uma reconfiguração da noção de experiência - categoria central no feminismo, sobretudo aquele que teve lugar em nosso país nos anos 1970.

Ao observar os coletivos e encontros universitários de diversidade sexual e de gênero, bem como os de negros e negras, Lima $(2019 ; 2020)$ tem notado como as articulações e as mediações das diferenças ocorrem no campo desses coletivos. Nessa perspectiva, os coletivos universitários emergem como lugares nos quais os sujeitos articulam subjetividades múltiplas e instáveis (HALL, 2000). Por esse mesmo motivo, as negociações entre diferenças tornam-se o cerne dessas organizações. Todavia, dada a centralidade que o corpo - considerado a partir das relações sociais de poder que o constituem - toma, pautar os afetos ganha especial importância na política das organizações. A construção de sentidos para o engajamento político mostra-se indissociável de um processo de reelaboração sobre si e sobre as relações sociais.

A centralidade do corpo e das emoções para além dos repertórios, mas para a produção mesma dos enquadramentos, foi também apontada por Gomes (2018) a partir de pesquisa sobre a Marcha das Vadias no Rio de Janeiro. Nessa direção, o acionamento da noção de interseccionalidade pode estar articulado à mobilização de outra noção, a de experiência. Não obstante, não se trata da mobilização de narrativas, experiências, a fim de construir discursivamente a igualdade, como se identificou nos grupos feministas e homossexuais da década de 1970 (MACRAE, 1990). O acionamento da experiência em afirmações como "a gente não é só negro, a gente é mulher, é bicha, é sapatão, é trans, é gay, é hetero...", que se tornam comuns atualmente em coletivos universitários, implicaria também lidar com várias diferenças - compreendidas como operantes na produção do sujeito e da subjetividade, mas de modo indissociável de aspectos estruturais, como o racismo, o machismo e a cis-heteronormatividade - e aprender a dar conta de todas as diferenças (LIMA, 2020).

Zanoli (2020) enfocou a trajetória de 20 anos de um grupo ativista da cidade de Campinas (SP), o Aos Brados!!!!, seguindo as relações de sua principal liderança e de seus membros com atores políticos e movimentos que tiveram origem em diferentes momentos políticos e não poderiam ser circunscritos a um único movimento - ativismos LGBT, negros, populares e periféricos. Desse modo, Zanoli (2020) enfatizou a rentabilidade analítica de cortar sua rede, considerando as relações entre esses movimentos, bem como o caráter produtivo dessas relações, e observou que uma série de grupos de "distintos movimentos sociais" tem investido em um enquadramento interseccional com foco no combate a todas as formas de opressão e nas relações entre 
"distintas formas de ativismo". O autor considerou que tal enquadramento poderia ser flexível e inclusivo o suficiente para ser definido como "master frame" (BENFORD; SNOW, 2000) enquadramento é a própria crítica às identidades e à ideia de que um movimento social construído a partir de uma dessas identidades daria conta das desigualdades sociais às quais estão sujeitos os indivíduos.

Além do acionamento da categoria interseccional ou da luta contra todas as opressões, temos deparado com uma multiplicação de categorias, como no acrônimo LGBTQIA+ e suas variações. Embora pareçam processos que caminham em direções opostas, temos trabalhado sobre a hipótese de que tais acionamentos são atravessados pelo deslocamento de uma ênfase nas identidades, baseada no essencialismo estratégico, para uma ênfase na experiência, com inspirações em teorias queer, decoloniais e/ou no feminismo negro. Tais acionamentos trazem ao centro as transidentidades, as lesbianidades e as bichas, sapatões e trans pretas e/ ou periféricas ou soropositivas, empoderadas e com formas de visibilidade renovadas (FACCHINI, 2018). Assim como as vadias e suas formas de apresentação e "coreografias transgressoras", descritas por Gomes (2018), trata-se de "corpos-bandeira".

Outra face da centralidade adquirida pelo corpo e pela experiência implica a relação entre ativismos, mercado e consumo. Examinando as transformações do feminismo negro brasileiro, Rios e Maciel (2018) notam também o impacto da geração mais jovem sobre o mercado e as relações de consumo, dado seu maior potencial no que diz respeito a influenciar opiniões, estilos de vida e comportamentos. Muitas das ações e formas de mobilização dos sujeitos convertidos em corpos-bandeira nos ativismos LGBT passam pela organização de festas - como Don 't Touch My Hair, Batekoo ou Amem -, que vêm sendo estudadas por Ribeiro (2017), nas quais o financiamento coletivo e o empreendedorismo estão presentes. Silva (2019) analisa como, em um circuito de atividades culturais e comerciais voltadas à comunidade negra na cidade de São Paulo, as atividades de consumo são traduzidas em experiências estético-afetivas de transformação e afirmadas como prática feminista, além de como a moda se torna uma importante ferramenta para a comunicação de processos de mudança cultural e política.

Em outra ocasião, Silva (2018) chamou atenção para a relação entre as transformações nas "mobilizações da população negra”, a experiência universitária e a produção cultural engajada, proporcionadas, em grande medida, pela ampliação do acesso ao Ensino Superior e pelas políticas de cultura. Silva localiza aí a produção de iniciativas que "não se atêm mais às formas rígidas de engajamento, mas estimulam a circulação por diferentes instituições, associações, coletivos, entre outras redes, concomitantemente, que lhes permitem uma intensa mobilidade, social, cultural, política e urbana" (2018, p. 26).

Figueiredo (2018) também associa a ampliação do acesso de estudantes negros, oriundos de camadas populares e indígenas às universidades a partir da implementação de ações afirmativas, à difusão do debate sobre desigualdades raciais para diferentes setores da sociedade, à ampliação do conceito de ativismo e ao alargamento do debate sobre o feminismo negro e sobre o empoderamento feminino em suas dimensões políticas e estéticas. Ao enfocar a Marcha das Mulheres Negras, a autora ressalta o acionamento e a ampliação do conceito de "bem viver", originado nas reflexões decoloniais, pela denúncia da falência do processo civilizador em curso.

\section{Sidestreaming e Coexistência de Repertórios e Enquadramentos}

Se a recusa a se classificar como um movimento, a plasticidade das formas de ação coletiva, a política prefigurativa e a recusa a operar com base na produção de consensos e de unidade política estão muito presentes nesse contexto, essas características seguem coexistindo com formas mais institucionalizadas de organização e de atuação (GOMES, 2018; BULGARELLI, 2017; CARVALHO; CARRARA, 2015; RIOS; MACIEL, 2018; FACCHINI, 2018; COACCI, 2018). 
Por exemplo, desde meados dos anos 2000, intensificou-se a incidência política de redes ativistas no Judiciário, com resultados importantes, como as decisões do Supremo Tribunal Federal (STF) sobre as "uniões homoafetivas", a constitucionalidade das cotas, a alteração de registro civil de pessoas trans sem necessidade de laudos, cirurgia ou decisão judicial, e a criminalização da homo e da transfobia. Trata-se, via de regra, de debates que enfrentam forte oposição social e nos âmbitos do Executivo e do Legislativo, como também ocorre com o da interrupção voluntária da gravidez.

Redes de advogados LGBTI e feministas tornaram-se atores estratégicos em batalhas judiciais contra projetos de lei reacionários e contra ações arbitrárias de chefes do Executivo em diversos níveis de governo, muitas vezes amparadas por atores do Judiciário. Associações científicas e conselhos profissionais igualmente se mantêm como atores fundamentais, apesar de serem agora, também, constantemente ameaçados, em batalhas contra ações e medidas reacionárias que se multiplicam, vindas de atores de extrema-direita ou de seus aliados presentes em múltiplas esferas do Executivo, do Legislativo e do Judiciário.

Embora com menos acesso a recursos e em um cenário político muito desfavorável, as organizações e conexões construídas no período de maior ênfase no ativismo por vias institucionais seguem procurando incidir politicamente, especialmente em espaços mais permeáveis. Ativistas negras(os), feministas e LGBT fortalecem sua organização no interior de outros movimentos sociais, como no MST, e seguem disputando espaço em partidos políticos e buscando representação por via eleitoral.

Com o aumento da visibilidade do conservadorismo, ganharam centralidade enquadramentos nos quais as coreografias mais irreverentes dos corpos-bandeira dão lugar à ênfase na dor e no sofrimento. Aqui emergem as figuras das mães, seja de LGBTI ou de jovens predominantemente negros mortos por agentes de Estado; das mulheres negras e pobres vitimadas pela violência relacionada a gênero ou pela restrição do abortamento legal; de LGBT periféricos(as), travestis e transexuais, pessoas intersexo e gays e trans vivendo com o HIV.

No âmbito das igrejas, como num reverso da politização reativa dos setores religiosos ao avanço dos direitos sexuais (VAGGIONE, 2017) e como reação à associação entre evangélicos e católicos a perspectivas reacionárias e/ou fundamentalistas, ganha espaço uma espécie de reinvestimento político no campo religioso, protagonizado por determinadas igrejas ou setores, especialmente entre protestantes e católicos. Assim, vemos eventos e publicações em torno de teologias feminista, queer ou negra; formação de redes ou frentes evangélicas pelo Estado de Direito, pela Igualdade de Gênero, pela Legalização do Aborto, ou de Grupos de Católicos LGBT e mesmo articulações ecumênicas ou inter-religiosas, como as Féministas ou a que teve lugar no $1^{\circ}$ Congresso de Igrejas e Comunidade LGBTI+, realizado em São Paulo, em 2019. Serra (2017) e Batista Silva (2019) se debruçam sobre a atuação de grupos católicos LGBT, mostrando como foram além da discussão sobre o que dizem ou não os textos sagrados, para disputar as práticas pastorais e os documentos produzidos pela própria igreja, de modo a afirmar a membresia católica de fiéis LGBT e fortalecer redes de caráter ecumênico.

\section{Considerações Finais: "Queremos Trazer de Volta seu Amor pela Política”7}

Os princípios das Muitas seguem como alicerce da nossa atuação: uma política de amor, feminista, antirracista e antiLGBTfóbica, em confluência com as forças do campo progressista, por diversidade, representatividade e transparência, em busca do bem comum, da radicalização da democracia e da desconstrução de privilégios de toda ordem. Não temos tempo para esmorecer nem direito de escapar da nossa própria responsabilidade. Vamos juntas? ${ }^{8}$ 
Iniciativas como a Muitas - que fez nascer experiências de covereança e a Gabinetona, mandato coletivo em três esferas do Legislativo a partir de Minas Gerais - e as mandatas coletivas da Juntas (Pernambuco) $)^{9}$ e da Bancada Ativista (São Paulo) emergiram a partir de 2015 em coligações que envolviam o Partido Socialismo e Liberdade (PSOL). Têm em comum propostas para o oferecimento de um contraponto à forma hegemônica de compreender a política, radicalizar a democracia e lutar contra todas as opressões. No maior colégio eleitoral brasileiro, a Bancada Ativista, composta por sete mulheres e dois homens com diferentes perfis pessoais e ativistas ${ }^{10}$, foi a décima candidatura mais votada para o Legislativo estadual paulista. A mobilização bem-sucedida de diversas experiências articuladas em uma candidatura coletiva, que se compromete a lutar contra todas as opressões, remete-nos à atual ênfase articulada entre experiência e interseccionalidade.

Iniciamos este artigo mencionando as dicotomias hierarquizadas presentes em acusações como divisionismo e identitarismo dirigidas aos movimentos que nos ocupam e o finalizamos com as experiências da Muitas, da Juntas e da Bancada Ativista. No percurso, passamos por noções de minorias, especificidades e emancipação, predominantes nos enquadramentos do momento de "centramento" em torno de sujeitos políticos estáveis no período de abertura e início da redemocratização. Passamos também pela predominância da articulação entre formalização das organizações, participação em redes internacionais, manejo do essencialismo estratégico, multiplicação de identidades políticas, manifestações de rua, incidência política e participação em espaços de diálogo socioestatal no momento pós-transição democrática.

Enfatizamos as críticas anticapitalistas e de ativistas mais jovens à institucionalização, ao essencialismo estratégico e à acomodação às gramáticas estatais presentes nesse período. Notamos sua radicalização no contexto que tem sido descrito como de "crise da democracia" ou "desdemocratização" (RIOS; MACIEL, 2018; PRADO; CORRÊA, 2018), com intensa valorização da experiência, da autonomia e da interseccionalidade, além da multiplicação de formatos de atuação, com coexistência de formatos institucionalizados e não institucionalizados, de formas de atuação individuais e coletivas e de campos discursivos de ação no interior de uma teia mais ampla, denominada campo progressista.

Como procuramos enfatizar, a interseccionalidade tem operado como um enquadramento flexível e inclusivo, que transbordou o movimento feminista e o feminismo negro e que tem atravessado vários "movimentos" - um "master frame", como sugere Zanoli (2020). Entendemos que a transversalização de agendas e formas de organização, bem como o alargamento do que é tido como ativismo, pode guardar relação com as trocas entre movimentos propiciadas por processos de participação no período anterior e, também, com a difusão de informações e teorias propiciada pela popularização do uso da Internet, do uso mais ativo de redes sociais e pela popularização e o enegrecimento do Ensino Superior.

Concordamos com Bringel (2018) quanto ao uso mais ativo de redes sociais implicar maior autonomia para a participação e maior necessidade de se engajar, e entendemos que tal engajamento - inclusive de indivíduos que muitas vezes são muito jovens e/ou não têm experiências pregressas de engajamento, em um contexto de erosão dos direitos e da própria noção de direitos - possa estar associado a outras características, indicadas pelo autor como o "imediatismo" e a "urgência permanente da ação". Todavia, pesquisas recentes indicam certo desencanto com o potencial das redes sociais (BULGARELLI, 2017; COACCI, 2018), bem como a percepção de que o encadeamento de experiência, visibilidade e redes sociais é importante, mas pode também produzir armadilhas (COACCI, 2018).

Concordamos também com Gomes (2018), Lima (2016) e Carmo (2018b) quanto à recusa a se reconhecer como movimento, à plasticidade e ao fato de muitas iniciativas serem pontuais e pouco duráveis responderem a necessidades dos sujeitos que se engajam atualmente. Os processos políticos de formação e articulações mais permanentes não deixaram de existir. Articulações e confluências entre formas 
institucionalizadas e não institucionalizadas estão presentes, seja no cotidiano do ativismo em âmbito local e regional, seja em grandes manifestações, como a que teve lugar a partir do encontro entre a I Marcha das Mulheres Indígenas e a VI Marcha das Margaridas em Brasília, em 2019. Tais mudanças exigem o esforço metodológico de seguir trajetórias de indivíduos na sua passagem por iniciativas muitas vezes fugazes e de entender os processos de formação via vivência.

Embora a fugacidade das iniciativas, a recusa a construir unidade política e a ênfase na política prefigurativa de parte importante dos ativismos contemporâneos rompam com nosso modo de compreender processos políticos visando à transformação, isso não exclui, como nas experiências da Juntas, a Muitas, da Bancada Ativista, entre outras, apostas em inovar na ocupação de espaços institucionais e nas formas de construir representações. Não exclui também possibilidades de se mover na direção de futuros e utopias, o que tem se dado por meio do deslocamento da ideia de minorias para o de maiorias políticas, como no enunciado da Muitas ou na noção de "bem viver", mobilizada pela Marcha das Mulheres Negras.

Assinalamos, por fim, a centralidade do corpo e da experiência, especialmente entre as formas menos institucionalizadas do "fazer política" nesses movimentos do atual contexto. Com isso, à luz de Gomes (2018), torna-se essencial pensar os processos políticos também como subjetivos, permeados por afetos, tendo o corpo como central aos engajamentos e enquadramentos. Por esse motivo, iniciamos este artigo enfatizando o engajamento ativista como processo de reinscrição subjetiva e possibilidade de tornar a habitar - e procurar transformar - um mundo marcado pela violência. Os movimentos abordados neste artigo, por sua relação mais direta com o corpo, a subjetividade e a experiência, constituem locus privilegiado para enfocar a interseccionalidade como um enquadramento que transborda o feminismo negro e mesmo os movimentos que nos ocuparam neste artigo.

Vivemos um momento político permeado por altas voltagens emocionais, no qual o terror é evocado frequentemente pela acelerada retirada de direitos sociais, trabalhistas, sexuais e reprodutivos, bem como pelo esvaziamento ou a destruição de projetos de futuro. A atual ênfase na experiência funciona, a um só tempo, como forma de contraste em relação às políticas de identidade do período anterior e forma de reencantar a política ${ }^{11}$, conectando-a ao cotidiano e a estruturas de poder que são compreendidas como diretamente incidentes sobre a vida dos sujeitos e daqueles(as) que consideram os(as) seus(suas).

\section{Contribuição dos Autores}

Problematização e conceitualização: Facchini R, Carmo IN, Lima SP; Metodologia: Facchini R, Carmo IN, Lima SP;Análise: Facchini R, Carmo IN, Lima SP; Redação: Facchini R, Carmo IN, Lima SP.

\section{Notas}

1. Note-se que a Carta de Princípios do MNU é anterior ao Estatuto da Criança e do Adolescente e que menor era uma categoria corrente nas políticas públicas aplicadas a crianças e adolescentes, especialmente aos negros.

2. Disponível em: http://www.portalmedico.org.br/pareceres/cfm/1985/5_1985.htm. Acesso em: 08.set. 2019.

3. A noção de cidadanização é tomada de empréstimo de Sérgio Carrara (2015), que a emprega em relação aos processos que envolvem sujeitos sociais cujas identidades remetem à diversidade sexual e de gênero em diferentes países ocidentais a partir 
dos anos 1960. Tal autor assinala, também, um aprofundamento, que então ainda podia ser pensado como atual, desse processo nos planos jurídico-políticos nacional e internacional. A categoria é, neste artigo, tomada para pensar o ápice de um processo de cidadanização compartilhado pelos sujeitos políticos que aqui nos ocupam, um processo que se dá, no caso brasileiro, entre meados dos anos 1980 e o final da década de 2000.

4. Embora hoje saibamos que as mesmas conferências de Cairo e Beijing foram o disparador da reação conservadora que se articula em torno de categorias como "ideologia de gênero", apenas no início dos anos 2010 a "onda conservadora" se torna perceptível para redes ativistas e passa-se a evocar sua existência crescentemente.

5. De acordo com Lima (2018), o crescimento da presença desses sujeitos nas universidades é acompanhado de uma diversificação de temas de pesquisa e de perspectivas epistemológicas acerca das questões relacionadas às "vivências" e "experiências", deslocando assim categorias de análises e bases teóricas estabelecidas em diversas áreas de conhecimento.

6. Segundo Benford e Snow (2000), a flexibilidade ou rigidez e o potencial de exclusão ou inclusão de um enquadramento pode influenciar em sua capacidade de evoluir para um master frame, ou seja, um modo de dar sentido à atuação política que pode passar a orientar diversos movimentos sociais.

7. Frase utilizada pela Bancada Ativista. Disponível em: https://votolegal.com.br/em/bancadaativista. Acesso em: 13 set. 2019. Quando da publicação deste dossiê, encontrava-se indisponível para acesso.

8. Disponível em: https://www.otempo.com.br/politica/gabinetona/gabinetona-4-parlamentares-em-um-mandato-coletivoaberto-e-popular-1.2125958. Acesso em: 08.set. 2019.

9. Disponível em: http://www.juntascodeputadas.com.br. Acesso em 20 jan. 2019.

10. De acordo com informações no site da Bancada. Disponível em: https://monicadabancada.com.br/. Acesso em 20 jan. 2019. Quando da publicação deste dossiê, encontrava-se indisponível para acesso.

11. Bila Sorj (2017) se refere a um reencantamento da política institucional a partir da participação político-eleitoral no campo feminista. Alargamos o argumento para um processo de reencantamento mais amplo da política a partir do diálogo com Carla Gomes (2018) acerca da centralidade do corpo e da experiência, bem como de nossas reflexões sobre a articulação entre experiência e intersecionalidade no contexto atual.

\section{Referências}

AGUIÃO, S. Fazer-se no "Estado": Uma etnografia sobre o processo de constituição dos "LGBT" como sujeitos de direitos no Brasil contemporâneo. Rio de Janeiro: EdUerj, 2018.

AGUIÃO, S.; VIANNA, A.; GUTTERRES, A. Limites, espaços e estratégias de participação do movimento LGBT nas políticas governamentais. In: LOPES, J. S. L.; HEREDIA, B (orgs.). Movimentos sociais e esfera pública: Burocracias, confrontos, aprendizados inesperados. Rio de Janeiro: CBAE, 2014.

AGUIAR, V. V. P. Somos todas margaridas: Um estudo sobre o processo de constituição das mulheres do campo e da floresta como sujeito político. 2015. Tese (Doutorado em Ciências Sociais) - Instituto de Filosofia e Ciências Humanas, Universidade Estadual de Campinas, Campinas, 2015.

ALMEIDA, R. A onda quebrada: Evangélicos e conservadorismo. Cadernos Pagu, n. 50, e175001, 2017. http://doi.org/10.1590/18094449201700500001

ALVAREZ, S. Para além da sociedade civil: Reflexões sobre o campo feminista. Cadernos Pagu, n. 43, p. 13-56, 2014. http://doi.org/10.1590/0104-8333201400430013 
BAGAGLI, B. P. Discursos transfeministas e feministas radicais: Disputas pela significação da mulher no feminismo. 2019. Dissertação (Mestrado em Linguística) - Instituto de Estudos da Linguagem, Universidade Estadual de Campinas, Campinas, 2019.

BATISTA SILVA, J. “Um lugar à mesa”: Estudo sobre a produção pastoral do ativismo católico LGBT brasileiro. 2019. Dissertação (Mestrado em Antropologia Social) - Instituto de Filosofia e Ciências Humanas, Universidade Estadual de Campinas, Campinas, 2019.

BENFORD, R. D.; SNOW, D. A. Framing processes and social movements: An overview and assessment. Annual Review of Sociology. v. 26, p. 611-639, 2000. https://doi.org/10.1146/annurev.soc.26.1.611

BLACKWELL, M.; NABER, N. Interseccionalidade em uma era de globalização: As implicações da Conferência Mundial contra o Racismo para práticas feministas transnacionais. Revista Estudos Feministas, v. 10, n. 1, p. 189-198, 2002. http://doi.org/10.1590/S0104-026X2002000100012

BRINGEL, B. Mudanças no ativismo contemporâneo: Controvérsias, diálogos e tendências. In: A luta popular urbana por seus protagonistas: Direito à cidade, direitos nas cidades. Rio de Janeiro: Fase, 2018, p. 20-29.

BULGARELLI, L. [ALERTA TEXTÃO] Estratégias de engajamento do movimento LGBT de São Paulo em espaços de interação on-line e off-line (2015-2016). 2017. Dissertação (Mestrado em Antropologia Social) - Faculdade de Filosofia e Ciências Humanas, Universidade de São Paulo, 2017.

CÂMARA, C. Cidadania e orientação sexual: A trajetória do grupo Triângulo Rosa. Rio de Janeiro: Academia Avançada, 2002.

CARDOSO, R. Movimentos sociais na América Latina. Revista Brasileira de Ciências Sociais, v. 1, n. 3, p. 27-37, 1987.

CARMO, Í. N. O perigo das dobras: Iconografias e corporalidades no feminismo contemporâneo. Sociologia e Antropologia, Rio de Janeiro, v. 8, n. 1, p. 193-222, 2018a. https://doi.org/10.1590/2238-38752017v817.

CARMO, Í. N. O rolê feminista: Autonomia, horizontalidade e produção de sujeito no campo feminista contemporâneo. 2018. Tese (Doutorado em Ciências Sociais) - Instituto de Filosofia e Ciências Humanas, Universidade Estadual de Campinas, Campinas, 2018b.

CARRARA, S. Moralidades, racionalidades e políticas sexuais no Brasil contemporâneo. Mana, v. 2, n. 2, p. 323-345, 2015. https://doi.org/10.1590/0104-93132015v21n2p323

CARVALHO, M. F. Nossa esperança é ciborgue? Subalternidade, reconhecimento e "tretas" na Internet. Revista Estudos Feministas, v. 25, n. 1, p. 347-363, 2017. https://doi.org/10.1590/1806-9584.2017v25n1p347

CARVALHO, M. F. L.; CARRARA, S. Ciberativismo trans: Considerações sobre uma nova geração militante. Contemporanea - Revista de Comunicação e Cultura, v. 13, n. 2, p. 382-400, 2015. http://doi.org/10.9771/18099386 contemporanea.v13i2.13865

COACCI, T. Conhecimento precário e conhecimento contra-público: A coprodução dos conhecimentos e dos movimentos sociais de pessoas trans no Brasil. 2018. Tese (Doutorado em Ciência Política) - Faculdade de Filosofia e Ciências Humanas, Universidade Federal de Minas Gerais, Belo Horizonte, 2018.

CORRÊA, S. O percurso global dos direitos sexuais: Entre "margens" e "centros". Bagoas - Estudos gays: Gêneros e sexualidades, n. 04, p. 17-42, 2009. 
CORRÊA, S. A "política do gênero": um comentário genealógico. Cadernos Pagu, Campinas, n. 53, e185301, 2018. http://doi.org/10.1590/18094449201800530001

COSTA, C. L. O tráfico de gênero. Cadernos Pagu, n. 11, p. 127-140, 1998.

DANILIAUSKAS, M. Não se nasce militante, torna-se: Processo de engajamento de jovens LGBT - Panorama histórico na cidade de São Paulo e cenário atual em Paris. 2016. Tese (Doutorado em Sociologia da Educação)

- Faculdade de Educação, Universidade de São Paulo, São Paulo, 2016.

DAS, V. O ato de testemunhar: Violência, gênero e subjetividade. Cadernos Pagu, n. 37, p. 9-41, 2011. http:// doi.org/10.1590/S0104-83332011000200002

DOIMO, A. M. A vez e a voz do popular: Movimentos sociais e participação política no Brasil pós-70. Rio de Janeiro: Relume Dumará; ANPOCS, 1995.

DOMINGUES, P. Movimento negro brasileiro: Alguns apontamentos históricos. Tempo, Niterói, v. 12, n. 23, p. 100-122, 2007. http://doi.org/10.1590/\$1413-77042007000200007

FACCHINI, R. Sopa de letrinhas? Movimento homossexual e produção de identidades coletivas nos anos 90. Rio de Janeiro: Garamond, 2005.

FACCHINI, R. Entre compassos e descompassos: Um olhar para o "campo" e para a "arena" do movimento LGBT brasileiro. Bagoas - Estudos gays: Gêneros e sexualidades, p. 131-158, 2009.

FACCHINI, R. Múltiplas identidades, diferentes enquadramentos e visibilidades: um olhar para os 40 anos do movimento LGBTI. In: GREEN, J. N. et al. (orgs.). História do Movimento LGBT no Brasil. São Paulo: Alameda, 2018, p. 311-329.

FACCHINI, R.; FRANÇA, I. L. Apresentação - Dossiê Feminismos Jovens. Cadernos Pagu, n. 36, p. 9-24, 2011. https://doi.org/10.1590/S0104-83332011000100002

FALCÃO, T. H. O. Memes, textões e problematizações: Sociabilidade e política a partir de uma comunidade de LGBT universitários no Facebook. 2017. Dissertação (Mestrado em Antropologia Social) - Instituto de Filosofia e Ciências Humanas, Universidade Estadual de Campinas, Campinas, 2017.

FERREIRA, C. B. C. O gênero do amor: Cultura terapêutica e feminismos. Cadernos Pagu. n. 47, e16472, 2016. https://doi.org/10.1590/18094449201600470002

FIGUEIREDO, A. Perspectivas e contribuições das organizações de mulheres negras e feministas negras contra o racismo e o sexismo na sociedade brasileira. Revista Direito e Práxis, v. 9, n. 2, p. 1080-1099, 2018. https://doi.org/10.1590/2179-8966/2018/33942

FRY, P.; MACRAE, E. O que é homossexualidade. São Paulo: Brasiliense, 1983.

GIACOMINI, S.; TERRA, P. Participação e movimento negro: Os desafios do "racismo institucional". In: HEREDIA, B.; LOPES, J. S. L. (orgs.). Movimentos sociais e esfera pública. Rio de Janeiro: CBAE, 2014.

GOMES, C. C. Corpo, emoção e identidade no campo feminista contemporâneo brasileiro: A Marcha das Vadias do Rio de Janeiro. 2018. Tese (Doutorado em Sociologia e Antropologia) - Instituto de Filosofia e Ciências Sociais, Universidade Federal do Rio de Janeiro, Rio de Janeiro, 2018. 
GONZALEZ, L. O movimento negro na última década. In: GONZALEZ, L; HASENBALG, C. Lugar de negro. Rio de Janeiro: Marco Zero, 1982, p. 9-66.

GONZALEZ, L. Por un feminismo afrolatinoamericano. Isis Internacional, Santiago, v. IX, p. 133-41, 1988.

GREEN, J. N. Além do carnaval: A homossexualidade masculina no Brasil do século XX. São Paulo: Editora Unesp, 2000.

GUIMARÃES, A. S. A questão racial na política brasileira (os últimos quinze anos). Tempo Social, v. 13, n. 2, p. 121-142, 2001. https://doi.org/10.1590/S0103-20702001000200007

GUTTERRES, A.; VIANNA, A.; AGUIÃO, S. Percursos, tensões e possibilidades da participação de movimentos de mulheres e feminista nas políticas governamentais. In: HEREDIA, B.; LOPES, J. S. L. (orgs.). Movimentos sociais e esfera pública. Rio de Janeiro: CBAE, 2014, p. 211-236.

HALL, S. Quem precisa de identidade? In: SILVA, T. T. (org). Identidade e diferença: A perspectiva dos estudos culturais. Petrópolis, Vozes, 2000.

LIMA, M. A produção de conhecimento em tempos de conflito: O lugar das Ciências Sociais. Revista de Antropologia, v. 61 n. 1, p. 95-102, 2018. https://doi.org/10.11606/2179-0892.ra.2018.145516

LIMA, S. P. Asbi, as gay, as trava, as sapatão tão tudo organizada pra fazer revolução! Uma análise socioantropológica do Encontro Nacional Universitário de Diversidade Sexual (ENUDS). 2016. Dissertação (Mestrado em Saúde Coletiva) - Instituto de Medicina Social, Universidade do Estado do Rio de Janeiro, Rio de Janeiro, 2016.

LIMA, S. P. “Nós negros e LGBT estamos aqui!”: Raça, gênero e sexualidade na ação política em universidades brasileiras. Conexão e Política, v. 8, n. 1, p. 71-89, 2019. https://doi.org/10.26694/rcp.issn.2317-3254. v8e1.2019.p71-90

LIMA, S. P. “A gente não é só negro!”: Interseccionalidade, experiência e afetos na ação política de negros universitários. 2020. Tese (Doutorado em Ciências Sociais) - Instituto de Filosofia e Ciências Humanas, Universidade Estadual de Campinas, Campinas, 2020.

LOPES, J. S. L.; HEREDIA, B. Introdução. In: LOPES, J. S. L.; HEREDIA, B. (orgs.). Movimentos sociais e esfera pública: Burocracias, confrontos, aprendizados inesperados. Rio de Janeiro: CBAE, 2014, p. 21-42.

MACHADO, L. Z. Feminismos brasileiros nas relações com o Estado: Contextos e incertezas. Cadernos Pagu, n. 47, e16471, 2016. https://doi.org/10.1590/18094449201600470001

MACRAE, E. A construção da igualdade: Identidade sexual e política no Brasil da abertura. Campinas: Editora da Unicamp, 1990.

MÍCCOLIS, L.; DANIEL, H. Jacarés e lobisomens: Dois ensaios sobre a homossexualidade. Rio de Janeiro: Achiamé, 1983.

PEREIRA, A. “O Mundo Negro”: A constituição do movimento negro contemporâneo no Brasil (19701995). 2010. Tese (Doutorado em História) - Instituto de Ciências Humanas e Filosofia, Universidade Federal Fluminense, Niterói, 2010.

PRADO, M. A. M.; CORRÊA, S. Retratos transnacionais e nacionais das cruzadas antigênero. Revista Psicologia Política, v. 18, n. 43, p. 444-448, 2018 
RIBEIRO, B. Sobre flertes e afrontes: Entrecruzamentos de raça, gênero e sexualidade em duas festas na cidade de São Paulo. In: XI Seminário Internacional Fazendo Gênero; 13th. Women's Worlds, 2017, Florianópolis. Anais do XI Seminário Internacional Fazendo Gênero. Florianópolis: UFSC, 2017

RIOS, F. Institucionalização do movimento negro no Brasil Contemporâneo. 2008. Dissertação (Mestrado em Sociologia) - Faculdade de Filosofia, Letras e Ciências Humanas, Universidade de São Paulo, São Paulo, 2008.

RIOS, F. Elite política negra no Brasil. 2014. Tese (Doutorado em Sociologia) - Faculdade de Filosofia, Letras e Ciências Humanas, Universidade de São Paulo, São Paulo, 2014.

RIOS, F. A cidadania imaginada pelas mulheres afro-brasileiras: Da ditadura militar à democracia. BLAY, E.; AVELAR, L. (orgs). 50 anos de feminismo: Argentina, Brasil e Chile. São Paulo: Edusp, 2017, p.227-253.

RIOS, F.; MACIEL, R. Feminismo negro brasileiro em três tempos: Mulheres negras, negras jovens feministas e feministas interseccionais. Labrys, estudos feministas, 2018.

RODRIGUES, C. S.; PRADO, M. A. M. Movimento de mulheres negras: Trajetória política, práticas mobilizatórias e articulações com o Estado brasileiro. Psicologia \& Sociedade, v. 22, n. 3, p. 445-456, 2010. https://doi.org/10.1590/S0102-71822010000300005

RODRIGUES, R. C. C. GAAG Duque de Caxias: A emergência de um ativismo homossexual em terras fluminenses. In: GREEN, J. N. et al. (orgs.). História do Movimento LGBT no Brasil. São Paulo, Alameda, 2018, p. 177-191.

SANTOS, C. N. F. Três movimentos sociais urbanos no Rio de Janeiro: Padres, profissionais liberais, técnicos do governo e moradores em geral servindo-se de uma mesma causa. Religião e Sociedade, n. 2, p. 29-60, 1977.

SERRA. C. Viemos pra comungar: Os grupos católicos LGBT brasileiros e suas estratégias de permanência na Igreja. Rio de Janeiro: Metanoia, 2019.

SILVA, G. M. Cultura negra e empreendedorismo: Sensibilidades políticas a reivindicações econômicas eo engajamento através do mercado. Anuário Antropológico, v. 43, n. 1, p. 11-36, 2018. https://doi.org/10.4000/aa.2744

SILVA, G. M. Corpo, política e emoção: Feminismos, estética e consumo entre mulheres negras. Horizontes Antropológicos. v. 25, n. 54, p. 173-201, 2019. https://doi.org/10.1590/s0104-71832019000200007

SIMÕES, J. A.; FACCHINI, R. Na trilha do arco-íris: Do homossexual ao movimento LGBT. São Paulo: Editora Fundação Perseu Abramo, 2009.

SORJ, B. O "reencantamento" da política institucional: O feminismo na conjuntura conservadora do Brasil. Comunicação apresentada no congresso da LASA. Lima, Peru, 2017 (mimeo).

SWARTZ, M. J. Introduction. Local-level politics. Chicago: Aldine, 1968, p. 1-43.

VAGGIONE, J. M. La Iglesia Católica frente a la política sexual: La configuración de una ciudadanía religiosa. Cadernos Pagu, n. 50, e175002, 2017. https://doi.org/10.1590/18094449201700500002

VERGUEIRO, V. Por inflexões decoloniais de corpos e identidades de gênero inconformes: Uma análise autoetnográfica da cisgeneridade como normatividade. 2015. Dissertação (Mestrado em Cultura e Sociedade) - Instituto de Humanidades, Artes e Ciências Professor Milton Santos, Universidade Federal da Bahia, Salvador, 2015. 
ZANOLI, V. P. C. Fronteiras da política: Relações e disputas no campo do movimento LGBT em Campinas (1995-2013). 2015. Dissertação (Mestrado em Antropologia Social) - Instituto de Filosofia e Ciências Humanas, Universidade Estadual de Campinas, Campinas, 2015.

ZANOLI, V. P. C. “Bradando contra todas as opressões!”: Ativismos LGBT, negros, populares e periféricos em relação. Salvador: Devires, 2020.

\section{Sobre as Autoras}

Regina Facchini é pesquisadora do Núcleo de Estudos de Gênero Pagu da Universidade Estadual de Campinas (Unicamp). Cientista social pela Fundação Escola de Sociologia e Política de São Paulo (FESPSP) e doutora em Ciências Sociais pela Unicamp. Pesquisa sobre: movimentos sociais e coprodução do conhecimento científico; violência, sofrimento social e subjetivação.

Íris Nery do CARmo é cientista social pela Universidade Federal da Bahia (UFBA) e doutora em Ciências Sociais pela Universidade Estadual de Campinas (Unicamp), com período sanduíche na University of Massachusetts. Pesquisa sobre movimentos sociais, feminismos contemporâneos e produção de sujeitos políticos.

Stephanie Pereira de Lima é cientista social pela Universidade Federal do Rio de Janeiro (UFRJ) e doutora em Ciências Sociais pela Universidade Estadual de Campinas (Unicamp). Desenvolve pesquisas relacionadas aos temas: gênero e sexualidade, raça, ação afirmativa e movimentos sociais contemporâneos.

Recebido: 26 Out 2019

Aceito: 10 Jun 2020 